\title{
Let Archived Paraffin Blocks Be Utilized for Research with Waiver of Informed Consent
}

\author{
Yong-Jin Kim · Jeong Sik Park ${ }^{1}$ \\ Karam $\mathrm{Ko}^{2} \cdot$ Chang Rok Jeong ${ }^{3}$ \\ Department of Pathology, School of Medicine, \\ Kyungpook National University, Daegu; \\ 'Department of Philosophy, College of \\ Humanities, Kyungpook National University, \\ Daegu; ${ }^{2}$ Korea Study Group for Biomedical \\ Ethics, Seoul; ${ }^{3}$ Department of Ethics Education, \\ Teachers' College, Kyungpook National University, \\ Daegu, Korea \\ Received: January 5, 2018 \\ Accepted: February 7, 2018

\section{Corresponding Author} \\ Chang Rok Jeong, PhD \\ Department of Ethics Education, Teachers' College, \\ Kyungpook National University, 80 Daehak-ro \\ Buk-gu, Daegu 41566, Korea \\ Tel: +82-53-950-5868 \\ Fax: $+82-53-950-5947$ \\ E-mail: canthos@hanmail.net
}

\begin{abstract}
Advances in biomedical and genetic research have contributed to more effective public health improvement via bench-to-bed research and the emergence of personalized medicine. This has certainly showcased the importance of archived human tissues, especially paraffin-embedded blocks in pathology. Currently in Korea, undue legislative regulations of the Bioethics and Safety Act suspend and at times discourage studies from taking place. In this paper, the authors underline the value of paraffin blocks in the era of personalized and translational medicine. We discuss detailed clauses regarding the applicability of paraffin blocks from a legal perspective and compare Korea's regulations with those of other countries. The necessity for allowing waived consent and Institutional Review Board (IRB) approval will be argued throughout. The authors suggest that researchers declare the following to obtain IRB approval and waiver of informed consents: research could not be practically carried out without a waiver of consent; the proposed research presents no more than minimal risk of harm to subjects, and the waiver of consent will not adversely affect the rights and welfare of subjects; and research will not utilize a tissue block if only 1 is available for each subject, to allow future clinical use such as re-evaluation or further studies.
\end{abstract}

Key Words: Paraffin block; Bioethics and Safety Act; Pathology research; Human biospecimen; Written consent
Formalin-fixed paraffin-embedded blocks (hereinafter 'paraffin blocks') are human tissue derivatives obtained during routine diagnostic or therapeutic procedures in hospitals. Tissues procured from patients are referred to the pathology department, cut into sections, and embedded into paraffin blocks for histopathologic examination. The blocks are stored in the archives of pathology laboratories for many years to be available for possible tests and re-examinations.

Paraffin blocks also serve as legal proof of diagnostic or therapeutic procedures, such as surgery, having been carried out. Therefore, paraffin blocks are regarded as a part of the medical records for hospitals and are kept for at least 10 years in most hospitals. ${ }^{1}$ With increasing reliance on biopsy for diagnosis, tissue samples are collected daily and produced in astronomical numbers in hospitals all over Korea. Assuming that theses blocks have been retained since establishment of a hospital, millions of paraffin blocks may be archived in each hospital today.

Rapid advances in genomic and molecular research methods, such as extracting DNA from blocks and studying it in genetic research, have highlighted the value of paraffin blocks. Linking paraffin blocks with existing clinical databases in biomedical research will not only save time for research, but is also safe and does not cause any physical or psychological harm to patients. This type of biospecimen archival research was responsible for finding the link between lung cancer and smoking, identification of $B R C A 1$ and $B R C A 2$ genes, advances in breast cancer research, and many other bench-to-bed findings. Research using such biospecimens can allow prediction of toxicity, evaluation of gene expression in normal and diseased tissue, and study of biomarkers for assessing therapeutic efficacy, and assist in clinical research to evaluate patient risk stratification, prognostication, and pharmacogenomics. ${ }^{2}$ This potential will enhance the quality of medicine and hasten developments in curing disease, thereby improving the health of the general public. The enormous potential of achieving medico-scientific discoveries by attaining diverse biodata from a clinical database without any risk to subjects makes paraffin block research invaluable.

These potentials can change and overcome current limitations 
faced in hospitals between screening and treatment in diverse fields of clinical practice. They will also lead to improved personalized treatment and the development of more targeted and efficient drugs. Because hospitals have stored an immense number of biospecimens over the years, research utilizing these materials is key to improving public health and bringing medicine to a new level.

However, for such beneficial research to be launched in Korea, it must first gain consent and approval via Institutional Review Board (IRB) review, according to the current Bioethics and Safety Acts. However, the existing legislation on human biospecimens is ambiguous. Judgements rely on how a committee interprets the act; often, research is not approved and therefore discouraged.

The authors examine the current standpoint of Korea's Bioethics and Safety Acts and compare it with those of other countries that hold different perspectives on research utilizing paraffin blocks. We then suggest ethical and legal ways to utilize paraffin blocks in research.

\section{EXEMPTION OF WRITTEN CONSENT FOR RESEARCH OF INSTITUTIONAL REVIEW BOARD}

Human derivatives defined in the 'Bioethics and Safety Act' (hereafter abbreviated as the 'Bioethics Act', 2015 Chapter 1 General, Article 2) are plasma, chromosomes, DNA, RNA, proteins, and the like derived from human body constituents. According to this act, research using paraffin blocks defined as human derivatives is required to obtain the consent of the provider and approval of an institutional committee. ${ }^{3}$ Such regulation seems logically applicable when research requires collection of tissue or any other form of human derivatives directly from subjects.

Currently in Korea, however, human derivatives in paraffin blocks are not collected for research purposes, but are procured for clinical diagnosis and treatment. During the process of procurement, tissue is extracted with patient consent. In addition, tissue is a disposable human derivative in accordance with Article 2 clause 5 of the Wastes Management Act (body tissue obtained in hospital). Thus, a consent for surgery should be considered consent to "extraction" and result in a legal process for treatment of "extracted material." Consenting to extraction should be seen as abandoning the tissue once the original purpose, for example surgical operation, has been fulfilled. It is questionable whether additional consent of the material provider (patient) is needed when using material that has been abandoned or agreed to be discarded for research. This differs from human derivatives extracted for research purposes, which require consent from participants before a study can commence. Conversely, if the patient wants to dispose of his/her surgically extracted tissue and/or did not wish for it to be used for research, use of the tissue would require additional consent. Therefore, some IRB committees assert that paraffin blocks for which consent for research with human derivatives has not been acquired cannot be used as a resource for study.

In fact, when an anonymous institutional committee inquired about the use of paraffin blocks for research, the Ministry of Health and Welfare's response was as follows. ${ }^{3}$

Question: I am wondering if a study using paraffin blocks should be deliberated in accordance with studies of human derivatives. When a paraffin block is produced for diagnostic purposes and the researchers would like to use it for further studies (including genetic tests) after diagnosis, do the researchers require approval of the plan and agreement before the research, such as research involving human subjects, or can they go ahead and proceed without the consent? In case of paraffin blocks, it is a kind of medical record and it is not produced for the purpose of research. So how should we review this research plan? ${ }^{4}$

Answer: Studies using paraffin blocks are also human-derived studies. Although the paraffin block after the medical diagnosis may be regarded as one of the medical records, the cost of the paraffin block production is paid by the patient and used for diagnostic purposes. Thus using the block for research purpose is an "unintended purpose use." Therefore, IRB review and consent is required in accordance with the study of the human derivatives. It is not exempted from acquiring consent, and necessary to review the research plan in accordance with Article 16 clause 3 of the Act and consider whether or not the written consent should be waived.

According to this answer, the following facts may be deduced: (1) paraffin block study is a study of human derivatives, and for the paraffin blocks initially intended for diagnostic purpose, use in research is considered an "unintended purpose use." Therefore, the IRB review and approval process is necessary in accordance with the study of human derivatives. (2) The decision of whether or not to allow waiver of consent may not be based on the fact that the material in question was "originally produced for diagnostic purpose," but should be made in accordance with Article 16 (3) of the Bioethics Act (risks and benefits in human subjects and obtaining written consent). This gives discretionary power to the IRB committee. While the answer to the question is accurate, many IRB committees still hesitate to exercise this right 
to discretion and instead understand that paraffin blocks cannot be used in research.

Bioethics Act Article 16 (Consent of Human Subjects) clause 1 stipulates that in cases of research involving human subjects, researchers must obtain written consent from research subjects prior to conducting the study. However, Article 16 clause 3 states, "Notwithstanding clause 1 , if the following requirements are satisfied, the written consent of the research subject may be waived with the approval of the IRB. (1) If the consent of the subject is not realistically feasible or has a serious impact on the validity of the study. (2) There is no reason that subject will refuse to give consent, and that without consent, the risk to the study."

According to the act, research using paraffin blocks may be exempted from the consent acquisition requirement for the following reasons: (1) it is practically not feasible to obtain the consent of the person who provided the paraffin block. Studies using paraffin blocks are mostly on cancerous tissues, and patients are often deceased. In fact, accessing medical records and personal information to obtain consent may be considered a violation of the provider's privacy. (2) There is no physical or psychological risk to the subject in research using paraffin blocks. As the research only utilizes tissues that have been already obtained and archived, the research cannot cause physical harm or pain. There is no personal contact; therefore, there is no risk of psychological harm. In addition, social anxiety due to the risk of identity exposure is also excluded if personal information is not used through anonymization. However, research that requires personal infor- mation should require consent.

When reviewing a plan for research utilizing paraffin blocks, the ethics of consent should be taken into account as well as that the block is considered a type of medical record. In other words, it should be considered whether the block to be used in a study infringes on a patient's right to medical treatment. There may be several blocks available, and using only 1 for research does not seem to raise any issue. However, if there is only 1 paraffin block of a patient, it may not be used for research. It may be necessary to respond to a patient request in the future or to further examine the tissue for the originally intended purpose. Because paraffin blocks are a type of medical record, these abovementioned guidelines are applicable only to blocks archived less than 10 years ago, since the legal retention period of medical records is 10 years.

In addition, studies using paraffin blocks may be exempt from IRB review under Article 36 (2) of the Bioethics Act depending on the study content. For the study of human derivatives, an IRB review waiver may be applicable in the following cases: research that does not collect or record personally identifiable information (PII); or research that uses the human body collected and stored by a biobank or that uses unidentifiable personal information unless verified through the biobank that provided the information. If these conditions are met, research using paraffin blocks is exempt from IRB review.

Table 1. Countries with bioethics legislative organizations and their views

\begin{tabular}{|c|c|c|c|}
\hline Country & Organization & Legislation/Publication & View on research using archived tissues \\
\hline Republic of Korea & National Bioethics Review Committee & Bioethics and Safety Acts (2016) & $\begin{array}{l}\text { IRB review and approval: required. } \\
\text { Consent: required, may be waived in specific } \\
\text { cases, with discretionary power of the IRB } \\
\text { committee. }\end{array}$ \\
\hline United States & $\begin{array}{l}\text { Department of Health and Human } \\
\text { Services } \\
\text { US FDA } \\
\text { HIPAA } \\
\text { SACHRP }\end{array}$ & $\begin{array}{l}\text { Common rule } \\
\text { Human subjects regulations } \\
\text { Privacy Rule, Security Rule } \\
\text { SACHRP Guideline }\end{array}$ & $\begin{array}{l}\text { Consent: If personal information is secured, can be } \\
\text { used without further consent. } \\
\text { IRB review and approval: exempted, if personal } \\
\text { information is secured and the tissue was not } \\
\text { collected for research purpose. }\end{array}$ \\
\hline Japan & Ministry of Health, Labour and Welfare & $\begin{array}{l}\text { Pharmaceutical Affairs Act and the Act } \\
\text { on the Safety of Regenerative Medicine }\end{array}$ & $\begin{array}{l}\text { No specific regulations on archived tissue research. } \\
\text { No consent needed after tissue has been acquired } \\
\text { (diagnostic/treatment purpose). }\end{array}$ \\
\hline Singapore & $\begin{array}{l}\text { Medical Council } \\
\text { Bioethics Advisory Committee }\end{array}$ & $\begin{array}{l}\text { Human Biomedical Research Act (2015) } \\
\text { Ethical Guidelines for Human Biomedical } \\
\text { Research (2010) }\end{array}$ & $\begin{array}{l}\text { Consent and IRB review may or may not be } \\
\text { required for residual/archived tissue } \\
\text { (case by case). }\end{array}$ \\
\hline United Kingdom & The Human Tissue Authority & Human Tissue Act (2004) & $\begin{array}{l}\text { Consent is not required. } \\
\text { IRB approval and review: not required, if personal } \\
\text { information is unidentifiable or anonymized. }\end{array}$ \\
\hline Australia & $\begin{array}{l}\text { National Health and Medical Research } \\
\text { Council }\end{array}$ & $\begin{array}{l}\text { National Statement on Ethical } \\
\text { Conduct in Human Research (2015) } \\
\text { Privacy Act (2001) }\end{array}$ & $\begin{array}{l}\text { Consent waiver is possible. } \\
\text { IRB approval and review: required. } \\
\text { Residual tissues considered as abandoned. }\end{array}$ \\
\hline
\end{tabular}

IRB, Institutional Review Board. 


\section{CASES IN OTHER COUNTRIES}

The regulations and guidelines published by each country differ, and at times the definition of terminologies and positions on exemption of informed consent vary in a way that confuses researchers and stakeholders. The main publications and legislative acts on archived tissue are summarized in Table 1.

\section{United States}

In the United States, there are several regulatory bodies that guide and regulate research on human tissue or biodata: the "Common Rule" and Secretary's Advisory Committee on Human Research Protection (SACHRP) in the Department of Health and Human Services (HHS), the U.S. Food and Drug Administration (FDA), and the Health Insurance Portability and Accountability Act (HIPAA). Researchers and institutions wishing to conduct research using biodata or human tissues in the United States must follow the regulations of the abovementioned bodies. These regulations allow a waiver of informed consent for research using archived tissues provided that personal information is secured.

The Common Rule states that research involving the collection or study of existing data, documents, records, pathological specimens, or diagnostic specimens may be exempt from these requirements if the information is recorded by the investigator in such a manner that subjects cannot be identified directly or through identifiers linked to the subjects (45 CFR 46.101(b) (4)). The FDA also indicates that it will refrain from enforcing regulations of informed consent in the following cases $^{5}$ : when a study uses leftover specimens; if the specimens are accompanied with only minimal clinical information (age, sex, and existing laboratory results); specimens are not individually identifiable; and the individuals caring for patients are different from and do not share information with those conducting the investigation.

The SACHRP, ${ }^{6}$ in the form of questions and answers, explains:

Question 1: Tissue biopsies were obtained for clinical diagnostic purposes, which have now been satisfied. The patients did not provide study specific informed consent for the research use of the tissue specimens. The hospital pathology department is willing to provide a portion of the remaining biopsy specimens to an investigator who will perform research assays. In order to allow matching with relevant clinical information, the specimens will be provided with identifiers such that the investigator can readily ascertain the identity of subjects. Is consent of the patient from whom the biopsy was taken (or waiver of consent) required for the secondary research use?

Answer: Yes. Under this scenario, informed consent of the subjects should either be obtained or waived under 45 CFR 46.116(d) because the samples are identifiable to the recipient investigator.

Question 2: Tissue biopsies were obtained for clinical diagnostic purposes, which have now been satisfied. The hospital pathology department is willing to provide a portion of the remaining biopsy specimens to an investigator who will perform research assays. The specimens will be coded such that the investigator will not be able to readily ascertain the identity of individuals. Is consent of the patient from whom the biopsy was taken (or waiver of consent) required for the secondary research use?

Answer: No. Under this scenario, neither consent nor waiver is required, because the activity is not considered to be research involving human subjects.

From regulations on waivers of informed consent, it is clear that in the United States, if a researcher does not know and is not provided with the personal information of a given sample, and if the material cannot be linked to the subject, then consent of the sample provider is not necessary. Furthermore, study of human derivatives without PII is excluded from studies of human subjects. This is considered nonhuman subject research and does not require IRB approval and review. ${ }^{7}$

In addition, the American Pathological Society (APS) has stated that diagnostic tissue and research tissue are different and that residual tissues after the diagnostic purpose has been fulfilled are regarded as abandoned. ${ }^{8}$ Thus, the APS permits study of specimens that have already fulfilled their original purpose and are now "abandoned," leaving the abandoned tissue free from the necessity of obtaining informed consent if it is to be used in research. Provided that personal information associated with a sample is secured, the abandoned or residual tissue can be used in research without IRB review and approval.

\section{Japan (no specific law for archived tissue research or} human tissue research)

In 2002, the Japanese Society of Pathology announced that archived tissue belongs to patients and that it is the responsibility of pathologists to respond to a patient's claim of ownership.

"The object of the pathological examination must be preserved in a form in which the dignity and privacy of the patient is protected. This consideration is also true for medical certificates, microscopic specimens, paraffin blocks or visual images. In addition, the organ, tissue, or microscopic specimen after the end of pathologic diagnosis will belong to the patient himself. Therefore, if there is a request for ownership it is necessary to return the material." 
However, in 2014, the Declaration was amended as follows. "Since the ethics of bioethics and medical ethics change according to the changes of times and society, the ethics committee of the Japanese Society of Pathologists invites external members to review them repeatedly, Considering the medical mission and the responsibility for society as pathologist, we have concluded that the 2002 decision was not necessarily appropriate."

Subsequently, even if there is a request for the return of all or part of the materials from a patient or his/her family, the archived specimen should not be returned or transferred unless proper use or management is guaranteed. It is difficult to deny that returning a specimen may interfere with the duties of hospitals and pathologists to explain the etiology and state of illness. Also, doing so is against public morals (goodwill and social order). Considering the value of paraffin blocks in medical research, the change in the position of the Japanese Society of Pathology is highly significant.

The current Bioethics Act of South Korea requires that individual researchers cannot collect or store human derivatives. Individual researchers are only allowed to collect relevant material for research, which is subject to approval by the institutional committee. The remaining research resources, if available, may be stored in a biobank. For these regulations to be effective in reality, a tissue bank should be established in all hospitals.

However, this is not the case in reality. Funding for the establishment of a tissue bank is not yet provided to all hospitals in Korea, and subsidies are also being decreased annually. It is likely that hospitals will continue to be unable to support a facility that does not generate revenue. Considering these points, it should be possible to facilitate the exchange of research and utilization of paraffin blocks stored in hospitals.

\section{Singapore}

A Bioethics Advisory Committee report released in 2002 and updated in 2015 indicates that human tissue banks in Singapore, in the past, were mainly built as an "incidental by-product of diagnostic procedures," indicating that samples were commonly obtained during medical treatment or diagnostic procedures. ${ }^{10}$ The report states that tissue donation should be considered an altruistic gift and the donor does not retain rights to the donated tissues or intellectual property rights.

Although every effort should be made to obtain consent for the use of leftover tissue for research, if consent cannot be obtained, then the IRB should have discretion to waive the consent requirement if the patient is not identifiable.

It is current practice to use biospecimens that remain after clinical requirements to validate laboratory tests or undergo clinical audit without consent of the providers and without IRB approval, if specimens are irreversibly deidentified. Singapore also allows biomedical research on human tissues for 1 or more researchers, as long as they receive IRB approval. In other words, individual researchers can collect and store human derivatives, once permitted by an IRB committee.

According to the act, the IRB may exempt requirement for consent in which the research involves no more than minimal risk to the research subject or sample provider and the biospecimen or health information is individually unidentifiable (part I, part II waiver of requirement for appropriate consent for human biomedical research involving human biological material or health information). ${ }^{11}$

Just as in the United States, Singapore also gives a waiver of consent when the health information is unidentifiable and if the research involves minimal risk to the sample provider.

\section{Australia}

In Australia, the National Health and Medical Research Council (NHMRC) regulates research on human tissues and approves ethical review processes established by institutional review committees. It updated and published a National Statement on Ethical Conduct in Human Research in 2015. ${ }^{12}$

There are 2 pathways that allow researchers to study human tissues. The full ethics application pathway involves prospective collection of biospecimens for research, whereas in the low-risk application pathway, prospective collection of biospecimens can be carried out with minimal risk to participants using stored specimens that would otherwise be discarded (e.g., after surgical operations, surplus to clinical requirements) (Chapter 3.4.11). The regulations indicate that if the specimen was obtained for clinical purposes and has been retained by an accredited clinical pathology service, it may be used for research purposes as long as the personal information of the provider is unidentifiable.

The guideline states that if a specimen is surplus to diagnostic requirements and would otherwise be destroyed, the personal information of the provider is protected, and there is no known or likely reason a participant would not have consented if they had been asked, a waiver may be considered (Chapter 2.3.10, 3.4.12). The NHMRC recognizes that it is impractical to obtain consent for biospecimens to be used in research when the material has been archived.

Korea does not have a separate pathway for archived tissue research or for low-risk research. A separate clause or ethical guideline for archived tissue will clarify possible questions and 
conflicting interests from researchers. Australia recognizes the difficulty for researchers in seeking informed consent from patients regarding archived tissue and allows waiver of consent for archived tissue research.

\section{United Kingdom}

The Human Tissue Act (HTA, 2004), proposed by the Human Tissue Authority, regulates the removal, storage, and use of human tissue. The Human Tissue Authority issues good practice guidance in codes of practice. It also licenses and inspects post-mortem pathological activities and storage of human tissue in hospitals. The Act provides a number of exceptions to the general rule that appropriate consent is required to store or use human tissue for scheduled purposes.

The Act states that tissues or organs removed by surgery might be considered "abandoned" by patients and can be used in ways seen fit by an institution. Samples of tissues collected from patients or subjects are considered "gifts" or "donations," although the research must be conducted according to ethical standards. ${ }^{13}$

Consent is not needed for the use of surplus or residual tissue taken from living patients that is left over after diagnostic or surgical procedures. It states that the use of residual tissue in research is exempted from consent provided that the research project has ethical approval (IRB approval) and the researcher cannot identify the tissue provider and is not likely to be able to do so in the future.

The Act also allows tissue from living or deceased subjects to be used for research without consent. Consent is not required for tissue that has been imported or comes from a body that has been imported. Consent is also not required for tissue that is or comes from the body of a person who died before the consent rules were enforced, and if at least 100 years have passed since the date of death.

In the United Kingdom, research on residual tissue is regulated in a similar manner as in the United States. Residual tissue is regarded as abandoned, thus requiring no informed consent in research as long as the confidentiality of personal information is secured and the information is not identifiable. Research on tissue with unidentifiable personal information is considered nonhuman subject research, and an IRB review and approval process is not required. However, if tissue is collected and stored for research purposes, research using these archived tissues requires IRB review and approval. In Korea, a clear distinction must be made between research using already-removed cells and tissues and research that requires an invasive method of collecting cells and tissues from a living person. Archived tissue research is safe and has no risk of psychologically or physically harming subjects. Provided that information is secured and unidentifiable, research using paraffin blocks should have fewer restrictions than research of human subjects dose.

\section{CONCLUSION}

In the era of personalized medicine, paraffin blocks are tremendously valuable and important. They serve as materials for biomedical, pharmaceutical, and genetic research. In this paper, the authors have highlighted the value of paraffin blocks in biomedical research and what role they may play if research is allowed with a less complicated and more reasonable approval process. To validate the limitations of the current Bioethics Act in Korea, the authors have presented the views of 5 countries regarding archived tissue research.

The current Bioethics Act has severe restrictions regarding research on archived tissues, and the authors suggest that archived tissue research should have a separate clause or guideline. All 5 countries discussed here allow waiver of consent or do not require consent to utilize paraffin blocks in research. Australia requires IRB review and approval. However, in the United States, Japan, and the United Kingdom, IRB review and approval are not required because paraffin block research is considered nonhuman subject research. The authors believe that IRB review and approval should be waived or not required because paraffin tissue research does not raise health risks for tissue providers provided that personal information is anonymized and unidentifiable. This will ease the unreasonable burdens researchers face before being given the chance to conduct research and in turn facilitates biomedical research advancements in Korea.

The authors suggest that paraffin blocks can be used in research while abiding by the Bioethics Act on the use of paraffin blocks and IRB review process in the following manner:

First, researchers should be able to explain that acquiring consent is impractical. For instance, the researcher should be able to explain that a sample is stored close to or past the date of legally required storage duration or that access to personal information for contact raises ethical questions. The sample provider or family members of the provider may not want to know findings or health-related information obtained from the sample. This act not only infringes on the human rights and autonomy of the provider, but may also psychologically harm the sample providers. However, reasons such as inconvenience regarding acquiring consent for a large quantity of paraffin blocks may not 
be considered viable excuses.

Second, the researcher must prove that the study is low risk and does not require consent. In other words, the research contents should be anonymized so as to not be connected with a sample provider's personal information.

Third, the paraffin blocks are to be used only if they are not the only sample of the provider, which will maintain residual tissue after the study. Because paraffin blocks serve as a type of medical record, they must be available at the provider's request to use for a certain period of time. If all 3 conditions are met, archived research using paraffin blocks should be allowed to be exempt from written consent and IRB review.

The authors hope IRB committees consider these assertions and encourage the use of paraffin blocks in research. In addition, the Korean Society of Pathology should establish more specific guidelines to safely protect the personal information of sample providers while promoting the advancement of biomedical research by allowing information-secured tissue research to be exempted from reviews and consents.

\section{Conflicts of Interest}

No potential conflict of interest relevant to this article was reported.

\section{REFERENCES}

1. Ryu YJ, Kim H, Jang S. Proposal for the development of a human biological material management system for research hospitals. J Korean Med Assoc 2012; 55: 292-303.

2. McDonald SA. Principles of research tissue banking and specimen evaluation from the pathologist's perspective. Biopreserv Biobank 2010; 8: 197-201.

3. Lee HJ. Review and consent for the human materials research in Bioethics and Safety Act. Kangwon Law Rev 2015; 45: 479-516.

4. Information Portal of Institutional Review Boards designated by the Ministry of Health and Welfare. 100 Questions and 100 answers. 2013 to 2014 collection of open writings 30. Sejong: Ministry of Health and Welfare, 2015.

5. U.S. Food and Drug Administration. Exception from general requirements for informed consent (21 CFR 50.23(e)) [Internet]. Silver
Spring: U.S. Food and Drug Administration, c2011-2017 [cited 2017 May 13]. Available from: https://www.gpo.gov/fdsys/pkg/FR2011-06-24/pdf/2011-15816.pdf.

6. Office for Human Research Protections. Attachment D: FAQ's terms and recommendations on informed consent and research use of biospecimens [Internet]. Rockville: Office for Human Research Protections, 2011 [cited 2017 May 8]. Available from: https:/ / www.hhs. gov/ohrp/sachrp-committee/recommendations/2011-october-13letter-attachment-d/.

7. e-CFR. Code of Federal Regulations (CFR) title 45 part 46 [Internet]. St. Louis: U.S. Government Publishing Office, 2017 [cited 2017 May 9]. Available from: http://www.ecfr.gov/cgi-bin/text-idx?tpl=/ ecfrbrowse/Title45/45cfr46_main_02.tpl.

8. Dry S. Who owns diagnostic tissue blocks? Lab Med 2009; 40: 6973.

9. Tsutsumi H. Question to a doctor (quote it from "idea four communication 82nd, pp. 4-9, 2012"). A question and answer about a pathological diagnosis and management: "the use of the pathology specimen of the breast cancer" question (Idea four, Ikuko Nakazawa) [Internet]. Toyoake: Fujita Health University, 2014 [cited 2018 Jan 1]. Available from: http://info.fujita-hu.ac.jp/pathology1/ideafour.pdf.pdf.

10. National Bioethics Advisory Committee. Human tissue for biomedical research: tumour banks [Internet]. Singapore: Academy of Medicine, 2002 [cited 2017 Jul 1]. Available from: http://ams.edu.sg/ view-pdf.aspx?file=media\%5C752_fi_611.pdf\&ofile=HumanTissu eForBiomedicalResearchTumourBanks.pdf.

11. Singapore Statutes Online. Human Biomedical Research Act 2015 (No. 29 of 2015) [Internet]. Singapore: Nanayang Technological University, 2015 [cited 2017 Jul 1]. Available from: http:/ /statutes.agc. gov.sg/aol/download/0/0/pdf/binaryFile/pdfFile.pdf?CompId: 03a5373e-148c-464f-90b8-526704d01c11.

12. The Royal College of Pathologists of Australasia. The ethical and legal issues in relation to the use of human tissue and test results in Australia. Surry Hills: The Royal College of Pathologists of Australasia, 2014.

13. The National Archives. Human Tissue Act 2004. Section 1-44 [Internet]. Norwich: Stationary Office Ltd., c2004 [cited 2017 Jul 4]. Available from: http://www.opsi.gov.uk/acts/acts2004/ukpga_20040030_en_1. 